\title{
TANTANGAN DAN HAMBATAN PEMBERDAYAAN MASYARAKAT DALAM PENGENDALIAN PENYAKIT TIDAK MENULAR DI DAERAH SEMI-PERKOTAAN : SEBUAH EVIDENCE BASED PRACTICE DI PADUKUHAN SAMIRONO, SLEMAN YOGYAKARTA
}

\section{Challenges and Barrier on Community Empowerment in Communicable Disease on Semi Rural Area : A Evidence Based Practice in Padukuhan Samirono, Sleman Yogyakarta}

\author{
La Ode Reskiaddin ${ }^{1}$, Vina Yulia Anhar ${ }^{2}$, Sholikah $^{3}$, Wartono ${ }^{4}$ \\ ${ }^{1}$ Program Studi Ilmu Kesehatan Masyarakat, Fakultas Kedokteran dan Ilmu Kesehatan Universitas Jambi. \\ 2 Program Studi Ilmu Kesehatan Masyarakat, Fakultas Kesehatan Masyarakat Universitas Lambung \\ Mangkurat \\ ${ }^{3}$ Balai Laboratorium kesehatan dan pengujian alat kesehatan Provinsi Jawa Tengah \\ ${ }^{4}$ Dinas Kesehatan Kabupaten Banyumas
}

\begin{abstract}
Abstrak
Tingginya prevalensi penyakit tidak menular merupakan beban yang sedang dihadapi di setiap negara. Pemberdayaan masyarakat merupakan salah satu strategi dalam membantu mengontol permasalahan kesehatan di masyarakat khususnya Penyakit tidak menular. Penelitian ini bertujuan untuk mengetahui tantangan dan hambatan melakukan pemberdayaan di daerah semi perkotaan. Penelitian ini menggunakan desain kualitatif. Data dikumpulkan melalui wawancara dan observasi. Subjek penelitian ini adalah masyarakat terutama kader kesehatan lansia dan para stakeholder di Padukuan Samirono. Hasil Penelitian menunjukkan bahwa tantangan dalam pemberdayaan di daerah semi perkotaan meliputi 1) Tingginya mobilitas dan padat aktivitas masyarakat, 2) Sistem birokrasi yang lama dan panjang, 3) Pengalaman intervensi terdahulu oleh beberapa institusi, 4) Minimnya data kesehatan. Hambatan yang ditemui pada saat program berlangsung, yaitu: 1) kurangnya pengalaman, keterampilan dan pengetahuan serta konsep diri kader kesehatan setempat; 2) kurangnya kesadaran masyarakat 3) karakteristik sosial dan budaya (agama, kondisi ekonomi); 4) Pesan kesehatan dari media massa; 5) Kurangnya dukungan stakeholder. Tantangan dan hambatan memberikan dampak negatif terhadap keberlangsungan program promosi kesehatan. Perlunya peningkatan kapasitas oleh tenaga kesehatan dan masyarakat yang berkelanjutan.
\end{abstract}

Kata Kunci : Hambatan, Tantangan Pemberdayaan Masyarakat, Semi-Urban

\begin{abstract}
The high prevalence of non infectious diseases is a burden that is being faced in each country. Community empowerment is one strategy to control health problems in the community, especially non-communicable diseases. This study aimed to determine the challenges and barriers on conducting community empowerment in semi-urban areas. This study used a qualitative design with narrative approach. Data was collected through interviews and observations. The subject of this study was the community member, including six health cadres of elderly, three stakeholders in Padukuhan Samirono and one health officer. Challenges in community empowerment in semi-urban areas include 1) high mobility and overcrowding community activities, 2) a longwinded bureaucratic systems, 3) previous intervention experience that conducted by another institutions, 4) lack of health data. Barriers found during the program, include: 1) lack of experience, skills and knowledge and self confidence of local health cadres; 2) lack of community awareness 3) social and cultural characteristics (religion, economic conditions); 4) health messages from the mass media; 5) lack of stakeholder support. Challenges and barriers contributed a negative impact on the sustainability of the health promotion program. Sustainable capacity building conducted by sustainable health officer and community health workers is needed.
\end{abstract}

Keywords: Barrier, Challenge, Community Empowerment, Semi-Urban

Korespondensi : La Ode Reskiaddin

Email : ld.reskiaddin@unja.ac.id 


\section{PENDAHULUAN}

Penyakit Tidak Menular (PTM) merupakan suatu masalah yang serius di berbagai negara di dunia. Menurut World Health Organization (WHO) bahwa 70\% kematian di seluruh dunia diakibatkan oleh penyakit tidak menular diantaranya penyakit jantung, stroke, kanker, diabetes dan penyakit paru-paru kronis, dan $82 \%$ dari 16 juta orang meninggal sebelum waktunya atau sebelum mencapai usia 70 tahun yang terjadi di negara berpenghasilan rendah dan menengah. WHO memproyeksikan kenaikan jumlah kematian PTM dari 36 juta di tahun 2008 menjadi 55 juta pada tahun 2030 jika tidak ada langkah efektif yang dapat mengendalikan hal tersebut $(1,2)$. Beberapa faktor penyebab tingginya angka prevalensi penyakit menular dikarenakan karena penggunaan tembakau, makanan yang tidak sehat termasuk asupan garam dan sodium yang tinggi, aktivitas fisik, kelebihan berat badan dan obesitas, dan penggunaan alkohol yang berlebihan, faktor risiko fisiologis utama adalah tekanan darah meningkat, peningkatan glukosa darah, hilangnya lapangan kerja karena kecacatan terkait PTM, dikombinasikan dengan durasi dan kompleksitas pengobatan PTM yang panjang menimbulkan tantangan tambahan terhadap pengurangan kemiskinan dan pembangunan berkelanjutan (16). Menurut Agaba penyakit menular yang paling sering terjadi adalah hipertensi, penyakit ginjal kronik dan diabetes (7).

Permasalahan kesehatan di Indonesia terkhusus PTM menjadi masalah yang cukup serius. Indonesia merupakan salah satu negara berkembang yang sedang menghadapi tantangan akibat PTM. Penyakit tidak menular di Indonesia secara signifikan meningkat tiap tahunnya. Jumlah kematian akibat penyakit tidak menular di Indonesia sebanyak 1.340 .000 kematian atau $73 \%$ dari jumlah kematian (2). Salah satu penyakit menular yang sedang dihadapi ialah diabetes dan hipertensi yang menunjukkan tren peningkatan setiap tahunnya. Berdasarkan data Riset Kesehatan Dasar (Riskesdas) tahun 2013, kasus hipertensi terjadi peningkatan prevalensi dari 7,6 \% tahun 2007 menjadi 9,5\% tahun 2013 (8). Di lain hal, pada tahun 2007, penyakit diabetes melitus juga meningkat dari $1,1 \%$ menjadi $2,1 \%$ pada tahun 2012.

Berdasarkan hasil analisis komunitas di Padukuhan Samirono, terdapat permasalahan kesehatan yang ditemukan diantaranya penyakit tidak menular yaitu diabetes dan hipertensi pada lansia. Jumlah kasus diabetes di Samirono sebanyak 24 orang dan 42 orang kasus hipertensi pada bulan Januari-Agustus 2016. Selain itu, terdapat 6 orang yang meninggal akibat penyakit diabetes. Berdasarkan hasil wawancara, faktor risiko penyakit hipertensi dan diabetes masyarakat daerah Samirono adalah faktor pola makan (suka mengkonsumsi gorengan), stres, umur dan kurang aktivitas fisik. Menurut Cheung dan $\mathrm{Li}$ menyebutkan bahwa penyakit diabetes dan hipertensi sering terjadi bersamaan dan biasanya memiliki faktor risiko yang sama seperti obesitas, stres oksidatif, resistensi insulin, dan tekanan mental (9). Di samping itu, permasalahan terkait kader lansia yang secara tidak langsung dapat mempengaruhi insiden diabetes dan hipertensi di Samirono diantaranya keterampilan kader dalam mengedukasi masyarakat terkait penyakit tidak menular, mengukur tekanan dan gula darah, partisipasi kader yang kurang serta sistem pelaporan dan pencatatan yang kurang sistematis.

Pengembangan kapasitas (capacity building) merupakan komponen yang penting dalam mempertahankan efektivitas program promosi kesehatan. Pengembangan kapasitas membantu individu dalam mengembangkan kepemimipinan, negosiasi dan pemecahan masalah kesehatan dan keterampilan membangun tim (10). Oleh karena itu, peningkatan kapasitas dibutuhkan untuk meningkatkan pengetahuan dan keterampilan kader Samirono dalam upaya pencegahan dan penatalaksanaan masalah penyakit tidak menular di daerah tersebut. Beberapa

Program pemberberdayaan masyarakat telah dilakukan berupa program intervensi berbasis promotif dan preventif yang ditujukan kader, guna meningkatkan pengetahuan dan keterampilan msayarakat dalam upaya pencegahan dan penatalaksanaan insiden penyakit tidak menular (hipertensi dan DM) di Padukuhan Samirono, Desa Caturtunggal, Kecamatan Depok, Kabupaten 
Sleman, Provinsi D.I. Yogyakarta. Namun dalam pelaksanaannya tidak mudah karena banyak tantangan dan hambatan yang dihadapi. Oleh karena itu, penelitian ini mendeskripsikan tantangan dan hambatan melakukan pemberdayaan di bidang Kesehatan pada daerah semi perkotaan.

\section{METODE}

Penelitian ini merupakan bagian dari rangkaian penelitian program promosi kesehatan. Penelitian ini menggunakan desain qualitative dengan pendekatan naratif. Program promosi kesehatan masyarakat melalui pemberdayaan masyarakat dilakukan selama trisemester pada tahun 2016 sampai 2018. Semester pertama dilakukan assessment data, semeseter kedua dilakukan kegiatan intervensi berupa kegiatan pengendalian Penyakit Tidak Menular dan semester ketiga berupa kegiatan monitoring dan evaluasi. Hasil kajian merupakan analisis berdasarkan hasil evaluasi akhir dari pelaksanaan kegiatan pemberdayaan masyarakat. Pengumpulan data melalui wawancara dan observasi. Subjek penelitian ini adalah masyarakat terutama kader kesehatan lansia dan para stakeholder di Padukuan Samirono.

\section{HASIL}

Berdasarkan hasil kegiatan promosi kesehatan yang dilakukan, maka ditemukan beberapa hambatan dan tantangan kegiatan pemberdayaan masyarakat di bidang kesehatan dalam upaya pencegahan penyakit tidak menular di Padukuhan Samirono, Kabupaten Sleman.

a. Hambatan Kegiatan Pemberdayaan Masyarakat

Hambatan yang ditemui pada saat program berlangsung, yaitu:

1) kurangnya pengalaman, keterampilan dan pengetahuan serta konsep diri kader kesehatan setempat.

Hasil observasi dan wawancara dari beberapa kader menyimpulkan bahwa beberapa kader tidak secara sukarela ingin menjadi kader, hanya berdasarkan penunjukkan dari kepala dusun. Selain itu, keterampilan dalam melakukan pelaporan dan penulisan data di posyandu yang kurang sehingga data yang dihasilkan tidak begitu baik. Selain itu, kurangnya kepercayaan diri kader dalam memberikan edukasi kepada masyarakat.

2) kurangnya kesadaran masyarakat

Masyarakat yang masih acuh tak acuh terkait dengan kegiatan program pemberdayaan yang dilaksanakan. Hal ini didasari oleh persepsi masyarakat yang menganggap bahwa kegiatan maayarakat yang baru hanya menghabiskan waktu mereka untuk melakukan aktivitas sehariharinya terutama bapak-bapak atau pemuda.

3) karakteristik sosial dan budaya (agama, kondisi ekonomi);

Masyarakat lebih memilih untuk beraktivitas yang menghasilkan uang atau pendapatan dibandingkan kegiatan pemberdayaan masyarakat di bidang kesehatan. Selain itu, kuragnya interaksi dengan masyarakat luar sehingga membuat provider kesehatan kesulitan masuk di forum-forum yang ada di masyarakat seperti kelompok PKK.

4) Pesan kesehatan dari media massa;

Berdasarkan hasil observasi kurangnya informasi kesehatan yang ada di masyarakat seperti poster atau media lainnya.

5) Kurangnya dukungan stakeholder.

Beberapa stakeholder terutama BKD desa dan beberapa ketua RT kurang berpartisipasi dalam kegiatan pemberdayaan masyarakat.

b. Tantangan Kegiatan Pemberdayaan Masyarakat

1) Tingginya mobilitas dan padat aktivitas masyarakat.

Berdasarkan hasil observasi bahwa masyarakat di daerah Samirono sebagian besar masyarakat pekerja, wirausaha dan mahasiswa. Masyarakat banyak menghabiskan waktu dari pagi hingga sore sehingga ketika diajak untuk berpartisipasi dalam kegiatan, sebagian besar beralasan 
lelah setelah mengerjakan pekerjaan dan ingin beristirahat.

2) Sistem birokrasi yang lama dan panjang. Hasil observasi dan wawancara menjukkan bahwa lamanya proses pengurusan suratmenyurat dan pelayanan yang berbelit-belit membuat fasilitator atau provider menunggu cukup lama untuk melakukan kegiatan pemberdayaan di masyarakat.

3) Pengalaman intervensi terdahulu oleh beberapa institusi.

Hasil wawancara dengan kepala desa dan ketua BKD menunjukkan bahwa program atau kegiatan baru yang akan dikembamgkan akan membuat kegiatan tersebut tidak berhasil karena masyarakat menolak, melainkan melanjutkan program yang sudah ada. Selain itu, program yang sudah dibuat oleh lembaga atau institusi yang terdahulu sebagai pembanding terhadap kegiatan yang akan dilakukan meskipun kegiatan tersebut tidak bersifat berkelanjutan.

4) Minimnya data kesehatan

Hasil observasi yang dilakukan bahwa data yang dimiliki masyarakat khusus kesehatan masih sangat minim terutama data-data di posyandu. Beberapa data yang hilang dan kurangnya pendokumentasian yang baik.

\section{PEMBAHASAN}

Pemberdayaan masyarakat merupakan sebuah proses yang dilakukan oleh faktor internal komunitas dengan memanfaatkan potensi yang ada di dalam masyarakat berupa sumber daya melalui proses fasilitasi. Selain itu, adanya dukungan sumber daya dari pihak luar. Tujuan akhir dari pemberdayaan masyarakat tersebut ialah keberdayaan masyarakat dalam melakukan identifikasi masalah kesehatan yang ada di dalam masyarakat tersebut dan mampu memecahkan masalah tersebut dengan berbagai program yang dibuat secara bersama-sama (11).

\section{Dalam pelaksanaan}

kegiatan

pemberdayaan masyarakat di bidang kesehatan tidak selamanya berjalan dengan baik. Banyak hambatan yang dihadapi oleh fasilitator atau tenaga kesehatan. Hambatan yang sering dihadapi adalah kurangnya kesadaran, pengetahuan, pengalaman dan konsep diri masyarakat khususnya kader dalam melakukan kegiatan yang berhubungan dengan permberdayaan masyarakat. Selain itu, keterampilan kader yang masih kurang dalam melakukan kegiatan. Upaya peningkatan kualitas kader yaitu dengan cara diberikan motivasi dan dilibatkan dalam kegiatan penyuluhan. Dalam rangka peningkatan kualitas tersebut, perlu dilakukan pengembangan dan pemberdayaan kader melalui kegiatan pelatihan. Adapun kegiatan pelatihan yang dilakukan yaitu, pemberian pengetahuan terkait hipertensi dan diabetes melitus. Pengetahuan merupakan salah satu faktor predisposisi dalam merubah perilaku individu. Pemberian pengetahuan ini bertujuan agar kader memiliki kompetensi ketika menghadapi masalah kesehatan yang dihadapi lansia, seperti hipertensi dan diabetes (12). Pelatihan diperlukan untuk meningkatkan pengetahuan, keterampilan dan kepercayaan diri kader. Bagi kader lama maupun baru, pelatihan dapat menjadi kegiatan yang informatif, menarik, sangat penting, dan membimbing mereka dalam merubah ke arah perilaku hidup sehat, serta memberikan kepercayaan diri untuk menginformasikan hasil pengetahuan dan keterampilan yang didapat kepada orang lain (13). Sejalan dengan penelitian Willock dkk pada tahun 2015 bahwa pelatihan dapat meningkatkan pengetahuan serta keterampilan kader dalam mencegah penyakit jantung (14).

Karakteristik sosial dan budaya masyarakat seperti agama dan kondisi ekonomi juga mempengaruhi dalam pelaksanaan kegiatan pemberdayaan masyarakat. Masyarakat yang memiliki penghasilan rendah lebih banyak mementingkan kegiatannya untuk memenuhi kebutuhannya sehari-hari. Faktor sosial ekonomi seperti pendapatan, pendidikan dan pekerjaan yang memengaruhi keberadaan sumber daya yang mempengaruhi kualitas hidup terutama di bidang kesehatan (15). 
Dukungan stakeholder juga menentukkan keberhasilan dari sebuah program pemberdayaan masyarakat yang dilakukan di masyarakat. laporan dari Population Health Interest Group mengidentifikasi pemberdayaan masyarakat menyangkut pembangunan koalisi antara profesional kesehatan dan kelompok masyarakat untuk memecahkan masalah masyarakat tertentu (16). Selain itu, keterlibatan stakeholder seperti kepala dukuh juga penting. Penerimaan terhadap program, serta adanya pengaruh kekuatan otoritas stakeholder, dapat menjadi lisensi untuk mempengaruhi masyarakat agar melakukan perubahan sesuai tujuan program. Dengan adanya keterlibatan berbagai pihak, seperti petugas Puskesmas, kader dan stakeholder, diharapkan sustainabilitas program ini akan tetap berjalan. Petugas kesehatan yang sering berbaur di antara komunitas dapat meningkatkan kelayakan dan dampak program dengan meningkatkan relevansi pesan promosi kesehatan, mendorong peningkatan perilaku kesehatan, mengatasi hambatan budaya dan akses, dan mendorong keterlibatan peserta (17). Sebaliknya, jika kurang dukungan dari strakeholder dan professional kesehatan akan menghambat dalam segala proses kegiatan sehingga mengakibatkan ketidakefisien dalam waktu, sumber tenaga dan keluaran pemberdayaan yang diharapkan.

Tingginya mobilitas dan padat aktivitas masyarakat menjadi salah satu tantangan yang sering dihadapi oleh provider kesehatan atau fasilitator. Hal ini disebabkan banyak masyarakat lebih mementingkan melakukan pekerjaan yang menghasilkan uang untuk kehidupan sehari-hari dibandingkan mengikuti kegiatan pemberdayaan yang dilakukan oleh tenaga kesehatan atau instansi lainnya. Selain itu, pekerjaan yang menghabiskan waktu cukup lama membuat masyarakat memilih untuk tetap tinggal dirumah untuk beristirahat dari rutinitas yang dilakukan sepanjang hari. Menurut Ulumiyah, dkk (2013) partisipasi masyarakat yang kurang karena tidak peduli dengan kegiatan yang dilakukan oleh fasilitator atau provider, lebih memilih bekerja dan beberapa faktor lainnya yang berdampak terhambatnya proses pemberdayaan (18).

Tantangan lainnya adalah beberapa data mengenai kesehatan di posyandu yang minim membuat fasilitator atau petugas kesehatan kesulitan dalam menentukan program pemberdayaan masyarakat yang akan dikembangkan sehingga sebagian besar kegiatan hanya berfokus pada keberlanjutan program yang sudah berjalan sebelumnya. Selain itu, Pengalaman intervensi terdahulu oleh beberapa institusi juga menjadi tantangan dalam pelaksanaan pemberdayaan masyarakat karena hal tersebut dijadikan sebagai pembanding dengan kegiatan yang akan dilakukan. Beberapa stakeholder menginginkan kegiatan yang sama dengan penganggaran biaya yang dibebankan oleh provider atau fasilitator. Menurut Cyril dkk menyebutkan bahwa beberapa tantangan dalam penerapan pemberdayaan masyarakat diantaranya infrastruktur sistem kesehatan dan penyediaan layanan yang buruk, staf dan sumber daya yang buruk, dan akses yang terbatas ke layanan kesehatan (17). Tantangan ini sering kali mengakibatkan kebutuhan komunitas yang tidak terpenuhi.

Administrasi birokrasi juga merupakan salah satu tantangan dalam pelaksanaan pemberdayaan masyarakat. Hal ini disebebkan karena proses yang cukup panjang dalam perizinan dari tingkat atas ke tingkat paling bawah, sehingga butuh waktu yang cukup lama untuk dapat berinteraksi dengan masyarakat. Beberapa masyarakat tidak mau menerima kedatangan fasilitator jika tidak memiliki izin karena ada beberapa pengalaman yang tidak menyenangkan sebagai bentuk pencegahan dari kejahatan sehingga masyarakat lebih waspada. Menurut Dwiyanto masih ada beberapa masalah yang sering dihadapi masyarakat dalam pelayanan publik diantaranya proses pelayanan yang lambat, berbelit-belit, biaya pelayanan yang mahal dan kurangnya kepastian waktu penyelesaian dalam pelayanan public, meskipun pelayanannya sudah berbasis teknologi informasi (19). 


\section{KESIMPULAN DAN SARAN}

Tantangan dan hambatan memberikan dampak negatif terhadap pelaksanaan dan keberlangsungan program promosi kesehatan. Tantangan dan hambatan tersebut sebagian besar berasal dari internal komunitas di Padukuhan Samirono. Perlunya peningkatan kapasitas oleh tenaga kesehatan dan masyarakat yang berkelanjutan serta penguatan monitoring dan evaluasi.

\section{DAFTAR PUSTAKA}

1. WHO. Global Action Plan for The Prevention and Control of Noncommunicable Diseases 2013 - 2020. Geneva, Switzerland: World Health Organization.; 2013.

2. WHO. Noncommunicable diseases country profiles 2018 [Internet]. World Health Organization.; 2018. Available from: https://apps.who.int/iris/handle/10665/2745 12. License: CC BY-NC-SA 3.0 IGO

3. Alwan A, MacLean DR, Riley LM, D'Espaignet ET, Mathers CD, Stevens GA, et al. Monitoring and surveillance of chronic non-communicable diseases: Progress and capacity in high-burden countries. Lancet [Internet]. 2010;376(9755):1861-8. Available from: http://dx.doi.org/10.1016/S01406736(10)61853-3

4. Bloom DE, Cafiero ET, Jané-Llopis E. The Global Economic Burden of Noncommunicable Diseases. Geneva, Switzerland: World Economic Forum 2011. 2012; (June 2014).

5. WHO. Global Health Risks: Mortality and Burden of Disease Attributable to Selected Major Risks. Geneva, Switzerland: World Health Organization; 2009.

6. Lim SS, Vos T, Flaxman AD, Danaei G, Shibuya K, Adair-Rohani $\mathrm{H}$, et al. A comparative risk assessment of burden of disease and injury attributable to 67 risk factors and risk factor clusters in 21 regions, 1990-2010: A systematic analysis for the Global Burden of Disease Study 2010. Lancet. 2012;380(9859):2224-60.

7. Agaba EI, Akanbi MO, Okeke EN, Agaba PA, Ocheke AN, Gimba ZM, et al. A survey of non-communicable diseases and their risk factors among university employees: A single institutional study. Cardiovasc J Afr. 2017;28(6):377-84.

8. Kemenkes. Riset Kesehatan Dasar (Riskesdas) 2013. Lap Nas 2013. 2013;1384.

9. Cheung BMY, Li C. Diabetes and hypertension: Is there a common metabolic pathway? Curr Atheroscler Rep. 2012;14(2):160-6.

10. Clearinghouse OPCOP. Capacity Building for Health Promotion. More Than Bricks and Mortar. 2002;4. Available from: http://capacitynet.region.waterloo.on.ca

11. Sulaeman ES, Karsidi R, Murti B, Kartono DT, Waryana W, Hartanto R. Model Pemberdayaan Masyarakat Bidang Kesehatan, Studi Program Desa Siaga. Kesmas Natl Public Heal J. 2012;7(4):186.

12. Hartati E, Wijayanti DY. Pemberdayaan Kader Posyandu Lansia di Semarang. In: rosiding Seminar Nasional Keperawatan Komunitas "Peran Perawat dalam Pelayanan Kesehatan Primer menuju Masyarakat Ekonomi ASEAN “. Semarang; 2015. p. 202-9.

13. Bradley $\mathrm{H}$ a, Puoane $\mathrm{T}$. Prevention of Hypertension and Diabetes in An Urban Setting in South Africa: Participatory Action Research with Community Health Workers. Ethn Dis. 2007;17(1):49-54.

14. Josiah Willock R, Mayberry RM, Yan F, Daniels P. Peer Training of Community Health Workers to Improve Heart Health Among African American Women. Health Promot Pract. 2015;16(1):63-71.

15. Hannon L. How to empower a community? Helping communities take control of their health destiny. Prev Med Reports [Internet]. 2019;13(2):166-9. Available from: https://doi.org/10.1016/j.pmedr.2018.12.00 1

16. HSE, Population Interest Group. Public health nursing in Ireland: demonstrating interventions from practice-validating public health nursing actions using the American Intervention Wheel. Lenus. 2013;(August).

17. Cyril S, Smith BJ, Possamai-Inesedy A, Renzaho AMN. Exploring the role of community engagement in improving the health of disadvantaged populations: A systematic review. Glob Health Action. 
2015;8(February).

18. Ulumiyah I. Peran Pemerintah Desa Dalam Memberdayakan Masyarakat Desa (Studi Pada Desa Sumberpasir Kecamatan Pakis Kabupaten Malang). J Adm Publik Mhs Univ Brawijaya. 2013;1(5):890-9.

19. Dwiyanto A. Mengembalikan Kepercayaan Publik Melalui Reformasi Birokrasi. Jakarta: PT Gramedia Pustaka Utama.; 2011. 